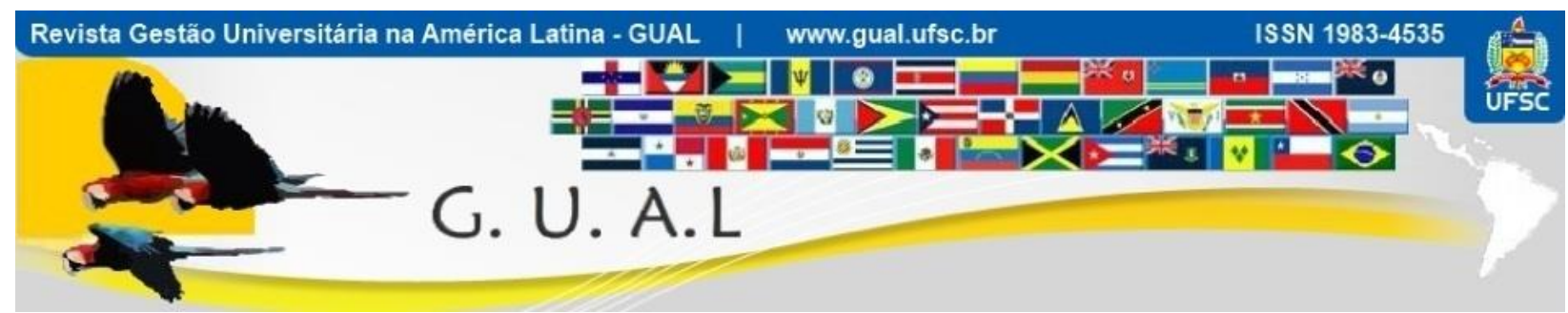

DOI: http://dx.doi.org/10.5007/1983-4535.2014v7n3p227

\title{
VALORES INDIVIDUAIS E COMPROMETIMENTO ORGANIZACIONAL: UM ESTUDO COM O CORPO DOCENTE DE INSTITUIÇÃO DE ENSINO SUPERIOR
}

\section{INDIVIDUAL VALUES AND ORGANIZATIONAL COMMITMENT: A STUDY WITH TEACHERS OF HIGHER EDUCATION INSTITUTION}

Saulo Henrique Brito Matos Martins, Mestre Universidade Ceuma - UNICEUMA saulohmartins@gmail.com

Anderson de Souza Sant'Anna, Doutor Pontifícia Universidade Católica de Minas Gerais - PUC-MG anderson@fdc.org.br

Recebido em 12/dezembro/2013

Aprovado em 25/julho/2014

Sistema de Avaliação: Double Blind Review

Esta obra está sob uma Licença Creative Commons Atribuição-Uso. 


\title{
RESUMO
}

Este estudo foi desenvolvido junto a instituição de ensino superior (IES). Nesse contexto, decidiu-se por realizar esta pesquisa, que teve como objetivo principal identificar relações entre os construtos valores individuais e comprometimento organizacional dos professores da IES pesquisada. Foram aplicados 550 questionários, sendo que dos 189 devolvidos, 157 foram considerados válidos. Os resultados quanto aos valores individuais revelaram que os valores mais presentes na equipe foram referentes aos tipos motivacionais benevolência, conformidade e autodeterminação. Quanto ao nível de comprometimento, identificou-se que o afetivo foi o mais presente no grupo pesquisado, seguido pelo normativo e, por último, o instrumental. Para verificar possíveis relações entre os valores individuais e o comprometimento organizacional, utilizou-se a análise de correlação de Pearson. Os resultados apuraram correlação positiva e significativa entre comprometimento e os tipos motivacionais hedonismo e segurança. $\mathrm{O}$ comprometimento normativo apresentou correlação positiva e significativa com os tipos motivacionais benevolência, conformidade, realização e segurança.

Palavras-chave: Comprometimento. Valores individuais. Corpo docente.

\begin{abstract}
This research was oriented to an institution of higher education (IHE). In this scenario, it was decided to conduct this research, which has as main objective to identify in a IHE, relationships between constructs Individual Values and Organizational Commitment of teachers. The results of the research in relation to individual values showed that the values present at the team refer to motivational types benevolence, conformity and selfdetermination. Regarding the level of organizational commitment, it was found that affective commitment is higher among the group surveyed, followed by normative commitment, and finally, the instrumental commitment. To verify the possible correlation between individual values and organizational commitment, it was used the Pearson correlation analysis between the two constructs. The results showed a significant positive correlation between commitment and motivational types hedonism and security. The normative commitment correlated positively and significantly with the motivational types benevolence, conformity, achievement and safety.
\end{abstract}

Key words: Commitment. Individual Values. Professional Bureaucracy. Teachers. 


\section{INTRODUÇÃO}

O setor de educação, mais precisamente o de instituições de ensino superior (IES), passou por significativo crescimento nos últimos anos. De acordo com dados do Instituto Nacional de Estudos e Pesquisas Educacionais (INEP), em 2000 existiam no país 1.180 IES, sendo 1.004 privadas e 176 públicas. O censo de 2009 registrou o número de 2.314 IES, sendo 2.069 privadas e 245 públicas.

Coutinho (2007) identificou em sua pesquisa que os clientes das IES, os alunos, consideram que o fator mais importante para garantir a qualidade do processo de ensinoaprendizagem é o professor, o profissional operacional conforme definido por Mintzberg. Além de ser o momento mais importante para o desenvolvimento dos alunos, o contato com o professor é também o momento mais frequente durante sua permanência na instituição, afirma o autor.

Haja vista o corpo docente de uma IES possuir significativa influência no processo executado e também ter importância no desempenho e qualidade do serviço, o nível de comprometimento desses profissionais com a organização surge como condição básica para sua efetividade.

Investigar o comprometimento dos docentes com os objetivos da organização passa a ser para as IES uma prioridade para garantir a qualidade dos serviços. Além disso, para melhor entendimento dessas equipes, é possível aprofundar na análise do perfil individual, o que pode ser feito através da investigação dos seus valores individuais, na medida em que, conforme descrito por Schwartz (2006), os valores de um indivíduo são aqueles que o guiam, que servem de base para suas decisões e também para avaliação de pessoas e situações que vivencia.

Após entender o perfil dos profissionais que compõem o corpo docente da IES e identificar o nível de comprometimento que os mesmos possuem com a organização, buscouse identificar neste trabalho se existe correlação entre esses dois construtos. Dessa forma, esta investigação pode ser sintetizada na seguinte questão de pesquisa: quais as relações entre os construtos valores individuais e comprometimento organizacional do corpo docente em uma instituição de ensino superior (IES)? 


\section{REFERENCIAL TEÓRICO}

O referencial teórico deste estudo abrangeu os construtos: valores individuais e comprometimento. Cada um deles será aprofundado nos subitens desse tópico, a partir da apresentação da evolução histórica dos estudos no tema, os principais conceitos e abordagens.

\subsection{VALORES}

Segundo Almeida e Sobral (2009), os estudos sobre valores têm sua origem na Filosofia, com os trabalhos de Sócrates, e evoluem para filósofos contemporâneos como Max Scheler e Johannes Hessen.

Tamayo (2007a), por sua vez, reconhece que as pesquisas sobre valores se intensificaram após os primeiros trabalhos de Shalom Schwartz nessa área, em 1987. E salienta que Schwartz foi o primeiro que conseguiu identificar que "o que diferencia um valor do outro é o tipo de motivação que ele expressa" (Tamayo, 2007a, p. 18).

Os estudos de Schwartz (1992) apresentam clara referência aos trabalhos de Milton Rokeach, um dos primeiros autores a definir o construto valores humanos. Com base nos estudos de Rokeach, Schwartz (1992, p. 1) conceitua os valores como sendo "o critério que as pessoas usam para selecionar e justificar ações e para avaliar pessoas, incluindo a si mesmo, e eventos".

Os estudos de Schwartz evoluíram e deram origem ao que é conhecido atualmente como a teoria dos valores humanos. A teoria de valores de Schwartz (1992) tem seis características principais que servem para apresentar o significado de valores nas nossas vidas. São elas:

a) Valores são crenças ligadas aos sentimentos: estão diretamente relacionados aos nossos sentimentos quando os valores são acionados;

b)valores referem-se a objetivos desejados que motivam a ação;

c) valores transcendem situações específicas. Por exemplo, valores como honestidade podem ser acionados diante de qualquer situação ou momento de vida;

d)valores servem como padrão ou critério para tomada de decisão;

e) valores são ordenados por grau de importância. 
Essas características estão presentes em todos os valores, sendo que o que distingue cada um deles é o tipo de objetivo motivacional que ele expressa (Schwartz, 2006a).

Nos seus estudos, Schwartz (1993) elaborou uma relação de sessenta e um valores para o cenário brasileiro. Cada um desses valores foi classificado de acordo com o objetivo motivacional que ele expressa, o que deu origem aos tipos motivacionais (Schwartz, 2006b). As pesquisas sobre os tipos motivacionais identificaram inicialmente oito tipos e após evoluírem, chegaram a dez tipos (Schwartz, 1992).

Cada um dos tipos motivacionais possui um direcionamento específico e está voltado para interesses individuais, coletivos ou mistos (Schwartz, 1992). O Quadro 1 apresenta os tipos motivacionais, os valores classificados em cada um dos tipos e o tipo de interesse que se referem.

\begin{tabular}{|c|c|c|}
\hline Tipos Motivacionais & Valores & Objetivo \\
\hline $\begin{array}{l}\text { Autodeterminação: relacionado com } \\
\text { aspectos de privacidade, independência e } \\
\text { individualidade. }\end{array}$ & $\begin{array}{l}\text { Sentido da vida, auto-respeito, liberdade, } \\
\text { autodeterminado, } \\
\text { independente }\end{array}$ & \multirow{4}{*}{ Individuais } \\
\hline 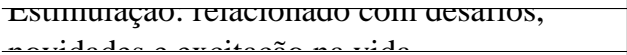 & Uma vida variada, uma vida excitante, audacioso & \\
\hline 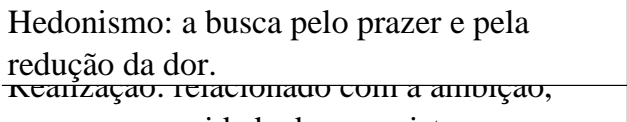 & 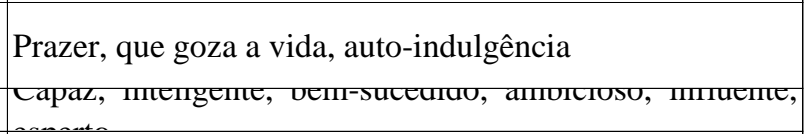 & \\
\hline $\begin{array}{l}\text { Poder: controle e autoridade sobre pessoas e } \\
\text { recursos. }\end{array}$ & $\begin{array}{l}\text { Preservador da imagem pública, reconhecimento social, } \\
\text { vaidade, riquezas, autoridade, poder social }\end{array}$ & \\
\hline $\begin{array}{l}\text { Segurança: sentimento de pertencer a algo, } \\
\text { estabilidade, harmonia e equilíbrio nas } \\
\text { relações e consigo. }\end{array}$ & $\begin{array}{l}\text { Segurança familiar, saudável, limpo, ordem social, } \\
\text { retribuição de favores, senso de pertencer }\end{array}$ & \multirow{2}{*}{ Mistos } \\
\hline $\begin{array}{l}\text { Universalismo: relacionado com os aspectos } \\
\text { do respeito ao bem-estar de pessoas e meio- } \\
\text { ambiente que o cerca. }\end{array}$ & $\begin{array}{l}\text { Harmonia interior, igualdade, sabedoria, justiça social, } \\
\text { um mundo em paz, sonhador, aberto, união com a } \\
\text { natureza, protetor do ambiente, um mundo de beleza }\end{array}$ & \\
\hline $\begin{array}{l}\text { Conformidade: relacionado com seguir } \\
\text { padrões. }\end{array}$ & $\begin{array}{l}\text { Respeitoso para com os pais e idosos, obediente, polidez, } \\
\text { autodisciplina; }\end{array}$ & \multirow{3}{*}{ Coletivos } \\
\hline $\begin{array}{l}\text { Tradicão: relacionado com tradições, } \\
\text { respeito a costumes de uma cultura ou povo. }\end{array}$ & $\begin{array}{l}\text { Humilde, ciente dos seus limites, moderado, devoto, } \\
\text { respeito pela tradição }\end{array}$ & \\
\hline $\begin{array}{l}\text { Benevolência: relacionado com os } \\
\text { sentimentos em relação ao outro com quem } \\
\text { se relaciona, lealdade, amizade, segurança no } \\
\text { relacionamento. }\end{array}$ & $\begin{array}{l}\text { Trabalho, honesto, responsável, leal, amizade verdadeira, } \\
\text { amor maduro, prestativo, uma vida espiritual, indulgente, } \\
\text { segurança nacional }\end{array}$ & \\
\hline
\end{tabular}

Quadro 1 Relação dos tipos motivacionais e os respectivos valores Fonte: Schwartz (1992).

Com a distribuição dos tipos motivacionais de acordo com o interesse que é representado no seu objetivo, Schwartz (1992) iniciou a elaboração de um modelo de representação das relações entre cada um dos tipos motivacionais. $\mathrm{O}$ autor identificou nas suas pesquisas que os tipos que tinham objetivo no indivíduo conflitavam ou eram 
antagônicos aos tipos motivacionais que focavam o coletivo. Com isso, Schwartz (1992) elaborou um modelo que representa o que é chamado pelo autor de estrutura bipolar dos valores. Nessa estrutura, apresentada na Figura 1, quanto mais próximos dois valores estiverem, mais sinergia existe entre eles; e quanto mais distantes na estrutura, mais antagônicos eles são.

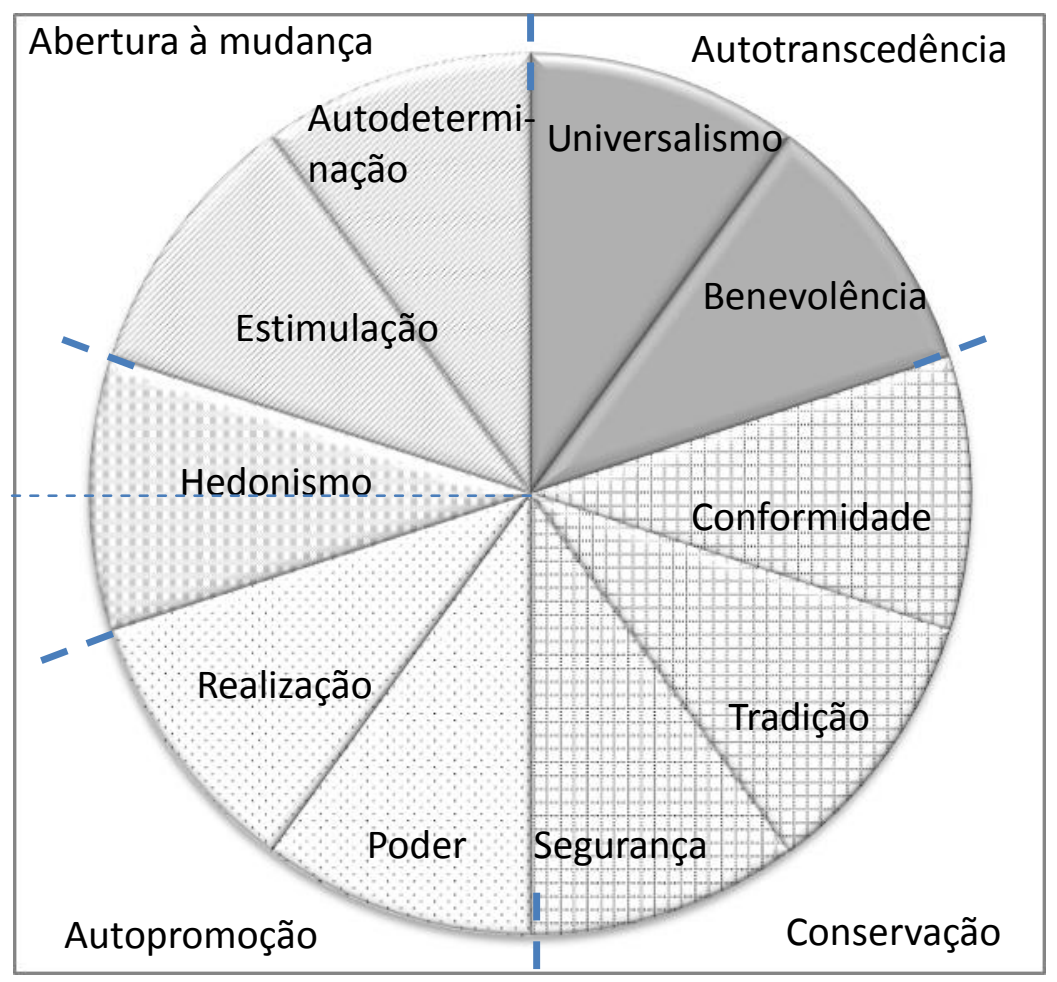

Figura 1 Estrutura de valores de Schwartz Fonte: Schwartz (1992).

Para representação dos valores semelhantes e opostos, o modelo apresentado na Figura 1 mostra que Schwartz (1992) agrupou os valores em dimensões de segunda ordem, sendo que quanto mais adjacente as dimensões estiverem, significa que os valores nela contidos possuem orientação axiológica semelhante, enquanto que dimensões opostas representam os valores opostos (Calvosa, 2011). O autor apresenta as dimensões criadas para agrupamento dos tipos motivacionais da seguinte forma:

a) Autopromoção: baseada na motivação do indivíduo para promover o seu próprio bemestar. Engloba os valores poder e realização; 
b)abertura à mudança: baseia-se na motivação do indivíduo para seguir seus próprios interesses intelectuais e afetivos, por caminhos incertos. Engloba os valores autodeterminação e estimulação;

c)autotranscedência: baseada na promoção do bem-estar dos outros e da natureza. Engloba os valores universalismo e benevolência;

d)conservação: baseada na busca pela preservação do seu status quo e das práticas tradicionais. Engloba os valores tradição, conformidade e segurança.

O tipo motivacional hedonismo é representado na estrutura bipolar de valores com uma linha tracejada que o separa entre as dimensões autopromoção e abertura às mudanças, demonstrando que o mesmo está orientado para ambas as dimensões (Calvosa, 2011).

A partir desse modelo passou a ser possível analisar como um conjunto de valores se relaciona com outras variáveis, não sendo mais necessário analisar cada um dos valores individualmente (Schwartz, 2006a).

Para se analisar os valores de uma determinada pessoa, foram desenvolvidos métodos que se aperfeiçoaram ao longo do tempo. Um dos principais instrumentos de mensuração de valores foi o Schwartz Values Survey (SVS), traduzido para o português como Inventário de Valores de Schwartz (Calvosa, 2011).

Os dados gerados pelo SVS podem servir para analisar tanto o próprio indivíduo, como também compará-lo a um determinado grupo social em que o questionário tenha sido aplicado, o que faz com que a ferramenta sirva para analisar possíveis fatores que sejam considerados estímulo para ações individuais ou coletivas (Calvosa, 2011).

Para este trabalho foi adotado o SVS, em função de ser uma escala amplamente aceita e testada em diferentes culturas, tendo sido validado no Brasil e considerado como denso e rico em opções de respostas (Calvosa, 2011).

Os estudos sobre valores buscam também identificar o grau de relação entre os valores humanos com outros construtos, como motivação, satisfação no trabalho e comprometimento (Ribas, 2010; Tamayo, 1998), construto objeto deste estudo e discutido no tópico a seguir.

\subsection{COMPROMETIMENTO}

Vários autores (Moraes et al, 2004; Bastos, 1993; Meyer \& Allen, 1991) relatam nos seus trabalhos que o volume de pesquisas sobre esse construto tem crescido muito nos últimos 
anos. Segundo Moraes et al. (2004), um dos estudos considerados como marco na evolução das investigações nessa área foi o trabalho de Mowday, Porter \& Steers, (1982), focado na análise dos antecedentes do comprometimento. Nesse trabalho, Mowday et al. (1982) apresentam uma visão de vários conceitos sobre comprometimento e afirmam que não existe consenso sobre a definição do tema.

Apesar das diferentes abordagens, Meyer \& Allen (1997) lembram que comprometimento sempre reflete um compromisso psicológico que liga o funcionário à organização, podendo ter origens diversas. Apesar de não fazer referência à origem desse compromisso, Bastos (1993) lembra que o significado de comprometimento que mais aparece nas pesquisas é o de engajamento em um curso de ação.

Hulin (1991 apud Bastos, 1993) afirma que comprometimento é um conjunto de fenômenos comportamentais e atitudinais voltados para a compreensão da adaptação e persistência do indivíduo na sua relação com o trabalho. Kiesler \& Sakamura (1966 apud Bastos, 1993) caracterizam comprometimento como um vínculo do indivíduo com atos ou comportamentos na empresa, fazendo com que as cognições relativas a tais atos se tornem mais resistentes a mudanças posteriores.

Moraes et al. (2004) comentam que, a partir dos anos 90, o comprometimento começa a ser estudado como um fenômeno multidimensional, o que é complementado pela afirmativa de Medeiros, Albuquerque, Marques, \& Siqueira (2005), ao lembrar que a visão de Meyer e Allen é a que melhor resume esse conceito ao chamar esses enfoques, ou dimensões, de componentes do comprometimento.

Da mesma forma que o comprometimento é definido por diferentes autores sem que haja consenso, as dimensões ou enfoques do comprometimento são apresentados por várias pesquisas (Allen e Meyer, 1990; Bastos, 1993; Etzioni, 1961; Gouldner, 1960; Kanter, 1968; Mowday et al., 1982; Sá \& Lemoine, 1999), sendo que, neste trabalho, são utilizadas as dimensões que foram defendidas por Meyer e Allen e apresentadas a seguir, visto que, segundo Medeiros et al. (2005), essa definição é internacionalmente aceita e validada em várias culturas.

\subsubsection{As dimensões do comprometimento}

Segundo Allen e Meyer (1990), as dimensões do comprometimento são: 
a)Comprometimento afetivo: ocorre quando o empregado se identifica com a organização e permanece porque quer;

b)comprometimento instrumental: quando o empregado permanece na organização porque precisa;

c)normativo: o sentimento de se sentir obrigado por ser a coisa certa a fazer.

Os estudos do comprometimento afetivo tiveram sua origem nos trabalhos comandados por Lyman Porter (Bastos, 1993; Medeiros et al., 2005).

O segundo enfoque mais estudado é o instrumental, que teve suas origens a partir dos trabalhos de Becker (1960) (Medeiros et al., 2005; Moraes et al., 2004). Meyer \& Allen (1997) concluem que quanto menor for a oportunidade de emprego, maior será o sentimento de perda, logo maior será o comprometimento instrumental.

A terceira dimensão de maior relevância nos estudos de comprometimento é a normativa, que teve origem nos estudos de Wiener (1982) e Medeiros et al. (2005). Segundo Wiener (1982), o comprometimento normativo está presente no indivíduo quando ele realiza suas tarefas da maneira certa, na medida em que tem a consciência de que isso é o certo a fazer.

Além de se aprofundarem na conceituação de comprometimento e também no entendimento das suas diferentes dimensões, com o passar do tempo os estudos sobre esse tema foram refinando também a forma como mensurar o grau de comprometimento das equipes.

Medeiros et al. (2005) propõem que o modelo de três componentes de Meyer \& Allen (1991) foi o mais aceito pelos pesquisadores ao longo dos tempos. Ainda segundo Medeiros et al. (2005), para mensurar o nível de comprometimento dos profissionais por meio do modelo definido nos seus trabalhos, os autores desenvolveram um questionário com 24 itens que foi depois reavaliado e serviu de base para desenvolvimento, por Meyer, Allen \& Smith (1993), de um questionário com 18 itens avaliados com base em uma escala Likert. Para fins deste estudo adotou-se o questionário de Meyer et al. (1993), em função de já ser validado no Brasil e também ser amplamente aceito pela comunidade internacional.

Tendo apresentado a base teórica necessária para este trabalho, será descrita a seguir a metodologia que foi utilizada para a realização da pesquisa e que serviu para as análises e conclusões sobre os construtos investigados. 


\section{METODOLOGIA}

De acordo com o objetivo geral deste estudo, que é identificar relações entre os construtos valores individuais e comprometimento organizacional em uma IES, optou-se por uma pesquisa de natureza quantitativa.

A IES onde foi procedida a pesquisa possui em seu quadro um total de 550 professores em diversas áreas do conhecimento. Para este trabalho, foram aplicados questionários à totalidade dos profissionais cadastrados na instituição.

No caso do construto valores individuais, foi utilizado o questionário SVS, composto de dois grupos de questões, o primeiro direcionado para valores terminais, que representam os estados finais desejáveis dos indivíduos, e o segundo voltado para os valores instrumentais, que representam os modos de conduta (Schwartz, 1992). Ambos são preenchidos por meio de escala Likert de nove pontos, iniciando-se em -1 e variando até sete.

Já para a mensuração do comprometimento, foi utilizado o questionário desenvolvido por Meyer et al. (1993). Esse questionário é composto de 18 questões, sendo seis para cada um dos tipos de comprometimento (afetivo, normativo ou instrumental). Para preenchimento do questionário, deve ser respondida cada questão em uma escala Likert de sete pontos, variando de um a sete.

Cabe mencionar que o questionário foi enviado, inicialmente, a um grupo de cinco professores, para pré-teste e verificação do seu entendimento.

Foram respondidos 189 questionários, já considerando os devolvidos impressos e também os eletrônicos. Desses 189 questionários, 32 foram descartados para a análise, pois apresentavam erros no seu preenchimento. Para descartar os questionários, adotou-se a premissa de que nenhum questionário seria aceito caso estivesse com respostas em branco, possuísse $100 \%$ das questões com mesma resposta ou que não tivesse sido respondido sem seguir as orientações de preenchimento. Por exemplo, no caso do questionário de valores, o respondente precisava escolher dois valores para atribuir nota -1 e dois valores para atribuir nota sete. Os questionários que não seguiram essa orientação foram descartados. Apesar de todos os questionários possuírem uma explicação sobre o método de preenchimento, alguns pesquisados não seguiram essas orientações ou não as entenderam.

Considerando-se os questionários descartados, chegou-se à amostra de 157 respondentes em uma população de 550 professores. Esses dados foram inseridos no programa International Business Machines (IBM) Statistical Package for Social Sciences 
(SPSS) Statistics, versão 20.0, e conseguiu-se calcular que com essa amostra obteve-se taxa de erro de 6,75\%, tendo-se um grau de confiabilidade de 95\%, valores considerados aceitáveis para a continuidade da análise.

Os resultados foram analisados com a aplicação do programa IBM SPSS Statistics, versão 20.0. Foram feitas as seguintes análises estatísticas:

a) Análise descritiva por meio de gráficos e tabelas de frequência das variáveis analisadas, estimativa de média, desvio-padrão, mediana das variáveis numéricas;

b)para verificar a possível relação entre os construtos comprometimento e valores pessoais, utilizou-se o coeficiente de correlação de Pearson. O nível de significância para se rejeitar a hipótese de nulidade será de 5\%, ou seja, considerar-se-á estatisticamente significante um valor de $\mathrm{p}<0,05$;

\section{APRESENTAÇÃO E ANÁLISE DOS DADOS}

A pesquisa foi realizada com professores de uma instituição de ensino superior. Do total de 550 professores, chegou-se a 157 questionários válidos para a análise.

A análise inicial realizada foi quanto ao perfil da população. Pode-se perceber uma pequena diferença entre a quantidade de docentes do sexo masculino (47\%) em comparação ao feminino (53\%). No quesito idade, tem-se que $69 \%$ do total indicaram possuir entre $31 \mathrm{e}$ 45 anos. Quanto ao estado civil constata-se predominância de indivíduos casados ou em união estável, totalizando $68 \%$, sendo os que não possuem parceiro, ou seja, os solteiros, divorciados ou viúvos, compõem 32\% da amostra. Para completar o perfil socioeconômico, tem-se que a renda média total apresentou grande quantidade (76\%) de indivíduos com até $\mathrm{R} \$$ $8.000,00$ de renda total.

No que diz respeito à análise do perfil profissional, $62 \%$ dos profissionais possuem até cinco anos de tempo de docência, o que caracteriza um perfil relativamente novo na atividade. No aspecto formação, tem-se que $42 \%$ são especialistas, $44 \%$ são mestres, $11 \%$ são doutores e $3 \%$ são pós-doutores.

\subsection{ANÁLISE DESCRITIVA DO CONSTRUTO COMPROMETIMENTO}

Quanto à análise do comprometimento organizacional, obteve-se os resultados apresentados na tabela 1 para cada uma das dimensões do construto. 
Tabela 1 Resultados por tipo de comprometimento

\begin{tabular}{ccccccc}
\hline Questão & $\mathbf{N}$ & Mínimo & Máximo & Mediana & Média & dp \\
\hline $\begin{array}{c}\text { Comprometimento afetivo: } \\
\quad \text { Questões 1,2,3,4,5,6 }\end{array}$ & 157 & 2,00 & 7,00 & 5,67 & 5,49 & 1,15 \\
$\begin{array}{c}\text { Comprometimento normativo: } \\
\text { Questões 13,14,15,16,17,18 }\end{array}$ & 157 & 1,50 & 7,00 & 4,83 & 4,71 & 1,30 \\
$\begin{array}{c}\text { Comprometimento instrumental: } \\
\text { Questões 7,8,9,10,11,12 }\end{array}$ & 157 & 1,00 & 7,00 & 2,83 & 2,98 & 1,21 \\
\hline
\end{tabular}

Fonte: dados da pesquisa.

Com base nos dados apresentados na Tabela 1, observa-se que o comprometimento mais presente na instituição é o comprometimento afetivo, com média igual a 5,49. Em seguida, tem-se o comprometimento do tipo normativo, com média igual a 4,71. Por fim, registra-se o comprometimento do tipo instrumental, com média 2,98.

As análises descritivas do construto comprometimento organizacional informaram elevado escore de comprometimento afetivo, seguido pelo comprometimento normativo. Essa análise foi feita levando-se em conta os dados da população pesquisada sem atentar para o perfil dos respondentes. Para mais aprofundamento da análise e para verificar se o perfil da amostra influencia os resultados do comprometimento organizacional, foi realizada análise de variância multivariada (MANOVA), cujos valores de p estão listados na Tabela 2. Pode-se observar que o coeficiente de determinação (R2) dos modelos é bem alto, indicando que o modelo matemático da análise está bem ajustado aos dados.

Tabela 2 Análise da influência do perfil no comprometimento

\begin{tabular}{cccccccc}
\hline Variável dependente & Sexo & Idade & $\begin{array}{c}\text { Estado } \\
\text { civil }\end{array}$ & Filhos & $\begin{array}{c}\text { Renda } \\
\text { média }\end{array}$ & Formação \\
\hline & $\mathbf{p}$ & $\mathbf{p}$ & $\mathbf{p}$ & $\mathbf{P}$ & $\mathbf{P}$ & $\mathbf{p}$ & $\mathbf{R 2}$ \\
\hline Afetivo & 0,268 & 0,268 & 0,926 & 0,609 & 0,359 & 0,0001 & 0,972 \\
Instrumental & 0,012 & 0,803 & 0,964 & 0,109 & 0,483 & 0,636 & 0,884 \\
Normativo & 0,698 & 0,006 & 0,331 & 0,018 & 0,013 & 0,0004 & 0,954 \\
\hline
\end{tabular}

Fonte: dados da pesquisa.

Pelos resultados identificados para p na Tabela 2, tendo-se que o nível de significância para se rejeitar a hipótese de nulidade será de 5\%, ou seja, considerar-se-á como estatisticamente significante um valor de $\mathrm{p}<0,05$, pode-se perceber que o comprometimento afetivo só é influenciado pelo nível de formação dos respondentes. Todas as demais variáveis analisadas estão com p>0,05. Em relação ao comprometimento instrumental, tem-se que apenas a variável sexo influencia o seu resultado. Quanto ao comprometimento normativo 
percebe-se que quatro variáveis influenciam o resultado final, sendo elas: idade, filhos, renda média e formação.

A variável sexo teve influência significativa apenas no comprometimento instrumental, tendo sido registrado média 3,18 para o sexo masculino e 2,80 para o sexo feminino.

O comprometimento instrumental, único com variação em função do sexo realmente identificada como significativa, exibiu diferença de cerca de $10 \%$ entre os respondentes dos sexos feminino e masculino. Os homens demonstraram ter mais comprometimento instrumental, tendo atingido média 3,18, enquanto as mulheres atingiram média 2,80.

Quanto à idade, percebe-se variação mais significativa apenas em duas faixas entre as pesquisadas. A faixa de 36 a 40 anos e a faixa de 51 a 55 anos apresentaram valores médios de comprometimento de 5,15 e 5,28, respectivamente. As demais faixas tiveram reduzida variação, apesar de poder ser notada tendência a que o comprometimento normativo fosse maior nas faixas etárias mais avançadas.

Outra variável analisada foi o número de filhos dos respondentes. Para essa faixa foi identificada também significância válida para o comprometimento normativo. o comprometimento normativo inicia-se em 4,39 para os profissionais que possuem um filho, atinge o nível de 5,18 entre os profissionais que possuem dois filhos e, a partir daí, reduz-se à medida que aumenta a quantidade de filhos, voltando para valor abaixo do identificado para o grupo que possui apenas um filho.

O comprometimento normativo realça um resultado que varia de acordo com a renda média dos respondentes, tendo a média mais baixa na faixa salarial inicial do grupo analisado. Os profissionais com renda até $\mathrm{R} \$ 2.000,00$ possuem média de comprometimento normativo igual a 3,54. A partir daí, percebe-se reduzida variação entre cada uma das faixas, com valor máximo no grupo que possui faixa salarial entre $\mathrm{R} \$ 8.001,00$ e $\mathrm{R} \$ 9.000,00$. Para essa faixa, foi identificada a média 5,74 para o comprometimento normativo.

Quanto à formação, identificou-se que existe diminuição do nível de comprometimento afetivo e normativo de acordo com o aumento do nível de formação dos respondentes. Apenas os profissionais com formação em pós-doutorado fogem a essa tendência, exibindo nível de comprometimento mais alto entre os grupos. 


\subsection{ANÁLISE DESCRITIVA DO CONSTRUTO VALORES PESSOAIS}

A análise descritiva dos valores pessoais foi realizada com o resultado agrupado de cada um dos 10 tipos motivacionais, de acordo com os valores que os compõem. A Tabela 3 mostra os resultados encontrados.

Tabela 3 Resultados dos valores individuais por tipo motivacional

\begin{tabular}{lcccccc}
\hline & N & Mínimo & Máximo & Mediana & Média & Dp \\
\hline BENEVOLÊNCIA & 157 & 3,4 & 6,3 & 5,5 & 5,4 & 0,6 \\
CONFORMIDADE & 157 & 2,5 & 6,3 & 5,5 & 5,3 & 0,8 \\
AUTODETERMINAÇÃO & 157 & 2,0 & 6,1 & 5,4 & 5,2 & 0,8 \\
SEGURANÇA & 157 & 2,8 & 6,3 & 5,2 & 5,1 & 0,7 \\
UNIVERSALISMO & 157 & 3,1 & 6,1 & 5,1 & 5,0 & 0,8 \\
REALIZAÇÃO & 157 & 1,7 & 6,3 & 4,3 & 4,5 & 0,9 \\
HEDONISMO & 157 & 0,3 & 6,3 & 4,7 & 4,4 & 1,4 \\
TRADIÇÃO & 157 & 1,2 & 6,2 & 4,4 & 4,3 & 1,1 \\
ESTIMULAÇÃO & 157 & 0,0 & 6,0 & 3,3 & 3,4 & 1,5 \\
PODER & 157 & 0,8 & 6,0 & 3,2 & 3,2 & 1,0 \\
\hline
\end{tabular}

Fonte: dados da pesquisa.

Para o grupo pesquisado, pode-se identificar a priorização dos valores individuais na seguinte ordem: benevolente $(5,4)$, conformidade $(5,3)$, autodeterminação $(5,2)$, segurança $(5,1)$, universalismo $(5,0)$, realização $(4,5)$, hedonismo $(4,4)$, tradição $(4,3)$, estimulação $(3,4)$ e poder $(3,2)$.

Conforme Schwartz (2006a), a teoria dos valores permite que o sistema de valores das pessoas seja tratado de maneira coerente, inclusive associando o conjunto de valores a outras variáveis organizacionais. Isso confirma ainda mais a importância da análise a ser feita a seguir, em que se buscará identificar correlações entre os valores individuais e o comprometimento organizacional dos profissionais pesquisados.

\subsection{CORRELAÇÕES ENTRE VALORES INDIVIDUAIS E COMPROMETIMENTO ORGANIZACIONAL}

Para investigar o grau de correlação entre os construtos valores individual e comprometimento organizacional, utilizou-se o coeficiente de correlação de Pearson entre eles. Lembra-se que o nível de significância para se rejeitar a hipótese de nulidade será de 5\%, ou seja, considera-se estatisticamente significante o valor de $\mathrm{p}<0,05$. Os resultados encontrados na análise de correlação de Pearson serviram também para validação ou rejeição de algumas hipóteses que nortearam este estudo. 
Vale também lembrar que um dos objetivos da pesquisa era identificar possíveis correlações entre os dois construtos, valores individuais e comprometimento organizacional, mas não identificar o grau em que cada valor individual influencia o comprometimento do corpo docente da IES.

Importante ressaltar que, segundo Gouveia, Santos e Milfont (2009), o coeficiente de correlação de Pearson (r) apresenta baixa correlação quando seu valor está entre 0,30 e 0,70, alto quando seu valor se encontra entre 0,70 e 0,90 e muito alto quando está acima de 0,90. Os autores chamam também a atenção para o fato de que variáveis oriundas da área da Psicologia, como é o caso de valores individuais e comprometimento, coeficientes de correlação considerados médios, são, na verdade, dos maiores encontrados nas pesquisas; e coeficientes acima de 0,30 são considerados uma exceção.

A primeira análise feita, demonstrada na Tabela 4, apresenta o coeficiente de correlação de Pearson para os 10 tipos motivacionais dos valores individuais com os três tipos de comprometimento investigados: afetivo, normativo e instrumental.

Tabela 4 Coeficiente de correlação de Pearson entre tipos motivacionais e os tipos de comprometimento

\begin{tabular}{|c|c|c|c|c|}
\hline & & Afetivo & Instrumental & Normativo \\
\hline \multirow{10}{*}{ 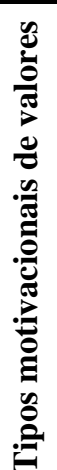 } & Autodeterminação & $-0,004$ & $-0,150$ & 0,005 \\
\hline & Benevolência & 0,130 & 0,014 & $0,248 * *$ \\
\hline & Conformidade & 0,078 & 0,028 & $0,200 *$ \\
\hline & Estimulação & $-0,045$ & $-0,079$ & $-0,068$ \\
\hline & Hedonismo & $0,172 *$ & 0,014 & 0,144 \\
\hline & Poder & 0,113 & $-0,046$ & 0,145 \\
\hline & Realização & 0,132 & $-0,114$ & $0,190 *$ \\
\hline & Segurança & $0,235 * *$ & 0,019 & $0,247 * *$ \\
\hline & Tradição & 0,011 & 0,026 & 0,156 \\
\hline & Universalismo & 0,016 & $-0,076$ & 0,086 \\
\hline
\end{tabular}

* Correlação significativa em 0,05 ; ** Correlação significativa em 0,01.

Fonte: dados da pesquisa.

Pelos dados apresentados, é possível constatar que apenas dois tipos motivacionais de valores encontram-se correlacionados com o comprometimento afetivo: hedonismo e segurança. Segurança se apresentando com a maior correlação com o comprometimento afetivo $(0,235)$.

Nenhum valor foi identificado com alguma correlação com o comprometimento instrumental. Quatro valores foram identificados com correlação com o comprometimento normativo, sendo eles: benevolência, conformidade, realização e segurança. 


\section{CONCLUSÕES}

O presente estudo teve como objetivo principal identificar em uma IES relações entre os construtos valores individuais e comprometimento organizacional do corpo docente.

Para desenvolvimento deste estudo, foi aplicado no corpo docente de uma IES um questionário dividido em três partes: levantamento do perfil socioeconômico, identificação dos valores individuais e verificação do grau de comprometimento organizacional. O questionário foi distribuído para 550 professores. Desse total, 189 foram devolvidos, tendo sido 157 considerados válidos.

No tocante à investigação referente aos valores individuais, os resultados encontrados apresentam a priorização dos tipos motivacionais na seguinte ordem: benevolência $(5,4)$, conformidade $(5,3)$, autodeterminação $(5,2)$, segurança $(5,1)$, universalismo $(5,0)$, realização $(4,5)$, hedonismo $(4,4)$, tradição $(4,3)$, estimulação $(3,4)$ e poder $(3,2)$.

Os três tipos motivacionais encontrados como mais presentes na pesquisa de Calvosa et al. (2011) foram os mesmos identificados no presente trabalho, com apenas uma alteração de ordem sequencial. No caso da pesquisa de Calvosa et al. (2011), os tipos motivacionais mais valorizados foram autodeterminação, benevolência e conformidade. E no presente estudo a autodeterminação foi o terceiro tipo motivacional mais valorizado. Da mesma forma, Moura et al. (2010) também encontraram os tipos motivacionais autodeterminação, benevolência e conformidade como os mais prioritários para docentes de IES.

Como segundo objetivo, este estudo buscou identificar o nível de comprometimento dos docentes da burocracia profissional investigada, no caso uma IES. Para isso, foi aplicado o questionário desenvolvido e validado por Meyer et al. (1993).

Os resultados permitiram identificar o comprometimento afetivo como o mais presente entre o grupo pesquisado, tendo atingido média 5,49 em uma escala de um a sete . Em seguida, registrou-se o comprometimento normativo, com escore 4,71, e, após, o comprometimento instrumental, com escore 2,98.

A dimensão afetiva do comprometimento demonstra que o empregado se identifica com a organização e permanece porque quer (Meyer \& Allen, 1991). Interessante citar também que a presente pesquisa foi realizada em uma IES no estado do Maranhão, Estado que apresenta a menor quantidade de mestres e doutores por mil habitantes (CAPES, 2012). Esse fato ajuda a entender o baixo escore para o comprometimento instrumental e escores mais altos para o comprometimento afetivo. As pessoas percebem outras oportunidades fora 
da empresa onde trabalham. Dessa forma, podem escolher onde trabalhar. Ou seja, se estão na empresa, estão porque querem ou, ainda por vínculos afetivos com seus proprietários, representantes e gestores.

Também foi analisado se o perfil da população exerce alguma influência nos níveis de comprometimento. Conforme afirmado por outros autores (Luthans, Baac \& Taylor, 1987; Mottaz, 1988), o comprometimento reduz à medida que o nível de educação se eleva. Os comprometimentos afetivo e normativo foram classificados como influenciados por essa variável. Em ambos ocorre redução dos escores encontrados à medida que aumenta a titulação.

Análises procedidas sobre valores individuais do corpo docente e seu nível de comprometimento, considerando cada uma das dimensões investigadas, fornecem os dados necessários para que seja respondida a pergunta de pesquisa deste estudo: quais as relações entre os construtos valores individuais e comprometimento organizacional do corpo docente em uma burocracia profissional, no caso específico, uma IES.

Com base na correlação de Pearson entre esses dois valores, constatou-se que no universo pesquisado não se identifica correlação de algum tipo motivacional com o comprometimento instrumental. Já o comprometimento afetivo apresentou correlação positiva com os tipos motivacionais hedonismo e segurança. Por sua vez, o comprometimento normativo correlacionou-se positivamente com benevolência, conformidade, realização e segurança.

Quando analisados os tipos motivacionais que estão correlacionados com o comprometimento afetivo, constatou-se que eles descrevem características de indivíduos que buscam prazer em fazer algo, querem fazer parte, buscam estabilidade, harmonia e equilíbrio nas relações.

Já a análise da correlação existente com o comprometimento normativo indicou tipos motivacionais que estão associados a características de realização, estabilidade, querer se relacionar bem com outras pessoas. As características presentes nos tipos motivacionais abstraídas nessa correlação destacam indivíduos que buscam fazer aquilo que é certo e mais estável, o que está muito associado às características do comprometimento normativo.

Em seus estudos, Tamayo et al. (2000), identificaram que os tipos motivacionais que apresentaram relação com as dimensões do comprometimento afetivo foram tradição, poder, estimulação, universalismo e conservação. No caso deste estudo, os tipos motivacionais 
relacionados ao comprometimento afetivo foram hedonismo e segurança. Outros autores também obtiveram relações fracas entre os tipos motivacionais e o comprometimento organizacional (FINEGAM, 2000; Ribas, 2010; Rodrigues et al., 2009). Essas fracas relações são justificadas por Mathieu e Zajac (1990) ao afirmarem que existem numerosas variáveis preditoras do comprometimento organizacional, como os valores, a posição do indivíduo na organização e características do trabalho.

A diferença de prioridades axiológicas apreendidas neste trabalho em relação a outras pesquisas que buscaram relações entre os construtos valores individuais e comprometimento pode ter como causa o perfil da organização em que a pesquisa foi aplicada. Esse fato abre possibilidade de ampliação deste estudo para outras IES.

\section{REFERENCIAS}

Allen, N. J.; Meyer, J. P. The measurement and antecedents of affective, continuance, and normative commitments to the organization. Journal of Occupational Psychology, 63, 1-8. 1990.

Almeida, F.; Sobral, F. O sistema de valores humanos de administradores brasileiros: adaptação da escala PVQ para o estudo de valores no Brasil. Mackenzie. RAM - Revista de Administração, São Paulo, 10(33), mai/jun, 2009.

ALMEIDA, Filipe Jorge Ribeiro de; SOBRAL, Felipe João Bera de Azevedo. O sistema de valores humanos de administradores Brasileiros: adaptação da escala PVQ para o estudo de valores no Brasil. RAM, Rev. Adm. Mackenzie (Online), São Paulo, v. 10, n. 3, Junho 2009. Disponível em <http://www.scielo.br/scielo.php?script=sci_arttext\&pid=S167869712009000300007\&lng=en\&nrm=iso>. accessado em 10 set. 2013.

Bastos, A. V. Comprometimento organizacional: um balanço dos resultados e desafios que cercam essa tradição de pesquisa. Revista de Administração de Empresas, São Paulo, 33(3), Mai/jun, 1993.

Becker, H. S. Notes on the concept of commitment. American Journal of Sociology, (66), 32-42, 1960.

Calvosa, M., Charney, P. L., Almeida, M. I. R., \& Serra, F. A. R. Quais são as prioridades axiológicas dos docentes de IES? Uma survey sobre a hierarquização de seus valores pessoais. In: Encontro Nacional da Associação Nacional de Pós-graduação e Pesquisa em Administração, Rio de Janeiro, Brasil, 2011.

Calvosa, M. Análise do planejamento estratégico pessoal a partir do autoconhecimento dos valores pessoais: a proposta do modelo das decisões axiológicas. Tese (doutorado) Universidade de São Paulo - USP, São Paulo.

Coutinho, F. C. C. Avaliação da qualidade dos serviços de uma instituição de ensino superior. 2007. 122 f. Dissertação (Mestrado) - Universidade Federal da Bahia, Salvador. 
Dias, D. V. Valores organizacionais, modelos e práticas de gestão de pessoas e comprometimento organizacional: um estudo em empresas selecionadas do setor siderúrgico mineiro. 2005. Tese (Doutorado em Administração) - Faculdade de Ciências Econômicas da Universidade Federal de Minas Gerais. Belo Horizonte.

Etzioni, A. A comparative analysis of complex organizations. Glencoe, New York: Free Press, 1961.

Finegam, J. E. The impact of person and organizational values on organization commitment. Journal of Occupacional and Organizational Psychology, v. 73, n. 2, p.1-49, 2000.

Gouldner, H. P. Dimensions of organizational commitment. Administrative Science Quarterly, 4, 468-490. 1960.

Gouveia, V; Santos, P; Milfont; IN Hutz, C. S. (org..). Avanços e polêmicas em avaliação psicológica. São Paulo: Casa do Psicólogo. 318 p. 2009

Kanter, R. M. Commitment and social organization: A study and commitment mechanisms in utopian communities. American Sociological Review, 33, 499-517, 1961.

Linzmeyer, S. O comprometimento organizacional e o desenvolvimento da carreira: um estudo sobre docentes universitários. 2009. 96 f. Dissertação (Mestrado) - Pontíficia Universidade Católica de São Paulo, São Paulo.

Luthans, F., Back, D., \& Taylor, L. Organizational commitment: Analysis of antecedents. Human Relations, 40 (4): 219-235, 1987.

Mathieu, J. E., Zajac, D. M. A review and meta-analysis of the antecedents, correlates, and consequences of organizational commitment. Psychologicol Bulletin, 108(2), 171-194, 1990.

Mattar, F. N. Pesquisa em marketing. Edição compacta, 3. ed. São Paulo: Atlas.2001.

Medeiros, C. A. F., Albuquerque, L. G., Marques, G. M., \& Siqueira, M. Um estudo exploratório dos múltiplos componentes do comprometimento organizacional. Revista Eletrônica de Administração, 11(1), 1-16, 2005.

Meyer, J. P., \& Allen, N. J. A three-component conceptualization of organizational commitment. Hum Res Manage Rev, 1, 61-89, 1991.

Meyer, J. P., \& Allen, N. J. Commitment in the workplace: theory, research and application. Thousand Oaks: Sage Publications, 1997.

Meyer, J. P., Allen, N. J., \& Smith, C. A. Commitment to organizations and occupations: extension and test of a three-component conceptualization. Journal of Applied Psychology, 78(4), 538-551, 1993.

Mintzberg, H. Criando organizações eficazes: estruturas em cinco configurações. São Paulo: Atlas. 1995.

Morais, J. H. M. Comprometimento e desempenho organizacional: um estudo hierárquico multinível (HLM) no sistema público da Bahia. 2004. 279 f. Dissertação (Mestrado), Universidade Federal da Bahia. Salvador. 
Motta, F. C., \& Pereira, L. C. B. Introdução à organização burocrática. São Paulo: Brasiliense. 1987.

Mottaz, C.J. Determinants of organizational commitment. Human Relations. 41 (6), $467-$ $482,1988$.

Mowday, R. T., Porter, L. W. \& Steers, R. M. Employee-organization linkages: the Psychology of commitment, absenteeism, and turnover. New York: Academic Press. 1982.

Pinsonneault, A.; Kraemer, K. L. Survey research in management information systems; an assessment. Journal of Management Information System, 1993.

Ribas, F. T. T. Somos frutos da nossa socialização: a influência dos valores humanos no comprometimento organizacional. 2010. 110 f. Dissertação (Mestrado). Universidade Federal de Santa Maria, Santa Maria.

Rodrigues, C., Vieira, K., Ribas, F., Tolfo, G., \& Catarina. G. Relação entre valores pessoais e comprometimento organizacional: o caso das empresas juniores de Santa Maria. Revista Brasileira de Gestão Organizacional, 8(2), 245-264, mai/ago. 2010.

Sá, M. A. D., \& Lemoine, C. Em matéria de comprometimento na empresa, sao os valores individuais que contam. In: Anais do $23^{\circ}$ Encontro Nacional da Associação Nacional de Pósgraduação e Pesquisa em Administração, Foz do Iguaçu, Brasil, 1999.

Schwartz, S. H. Basic Human Values. The Hebrew University of Jerusalem. 2006a.

Schwartz, S.H. A theory of cultural value orientations: explications and applications. Comparative Sociology, 5(2-3), 137-182, 2006.

Schwartz, S.H. Universals in the content and structure of values: theory and empirical tests in 20 countries. In: Zanna, M. (ed.). Advances in experimental social psychology. 25, 1-65. New York: Academic Press, 1992.

Tamayo, A. Contribuição ao estudo dos valores pessoais, laborais e organizacionais. Psicologia: Teoria e Pesquisa, 23(especial), 2007.

Tamayo, A., Schwartz, S. Estrutural motivacional dos valores humanos. Psicologia: Teoria e Pesquisa, 9, 329-348, 1993.

Tamayo, A., Souza, M. G. S., Vilar, L. S., Albernaz, J. V., Ramos, J. L., \& Ferreira, N. Relação entre os valores do empregado e o comprometimento organizacional afetivo. In: Encontro Nacional da Associação Nacional de Pós-graduação e Pesquisa em Administração, 1, 1-20, Florianópolis, Brasil. CD Rom ENANPAD2000.

Tamayo, A. Valores organizacionais: sua relação com a satisfação no trabalho, cidadania organizacional e comprometimento afetivo. RAUSP - Revista de Administração, 33(3), 5663, 1998.

Wiener, Y. Commitment in Organizations: a normative view. Academy of Management Review, 3(7), 418-428, 1982. 